\title{
PARTIAL BREAST NECROSIS AFTER MYOCARDIAL REVASCULARIZATION
}

\author{
Marcos Desidério Ricci ${ }^{1}$, Aricia Helena Galvão Giribela ${ }^{1}$, Alexandre Mendonça Munhoz ${ }^{2}$, José Roberto Morales Piato ${ }^{1}$, \\ Edmund Chada Baracat ${ }^{3}$
}

\section{INTRODUCTION}

Cardiovascular disease is the major cause of death among women. After menopause, 1 in 3 women will die from cardiovascular disease, but only 1 in 20 will die from cancer. ${ }^{1}$ Currently, myocardial revascularization is a common procedure even with minimally invasive angioplasty techniques. There are nearly 500000 surgeries performed for coronary insufficiency each year in the USA. ${ }^{2}$

The use of the internal mammary artery (IMA) as well as implants of the autologous saphenous vein is a common procedure in myocardial revascularization The major complications related to IMA are associated with the surgical wound, such as osteomyelitis and sternal dehiscence, which occur in $0.5 \%$ to $5 \%$ of cases. ${ }^{2}$ Infection of the median sternotomy is relatively infrequent but is a severe complication. Three decades ago, the mortality rate associated with such infections was close to $50 \%$, but now with the use of sternal debridement and reconstruction with various flaps, (rectus abdominis myocutaneous, pectoralis major myocutaneous, and latissimus dorsi) or single muscle flap, it is less than $10 \% .^{3}$

The association of cardiac surgery with partial or total breast necrosis is extremely rare, even in the presence of complex cardiac procedures, because the breast is a highly vascular organ. ${ }^{2,4-8}$ The IMA, also known as internal thoracic artery, is the major source (almost 60\%) of breast vascularization, but the breast is also irrigated by the external mammary artery and intercostals branches.

Sternotomy for cardiac surgery has been analyzed in retrospective studies, and breast necrosis was not found as a complication..$^{9,10}$ Median sternotomy was performed in 7,949 women at the New York University Medical Center, and no breast necrosis was reported. ${ }^{9}$ At that time however,

1. Department of Obstetrics and Gynecology, University of São Paulo School of Medicine, São Paulo, Brazil.

2. Division of Plastic Surgery, University of São Paulo School of Medicine, São Paulo, Brazil.

3. Ginecology - University of São Paulo School of Medicine, São Paulo, Brazil. Email: desiderion@uol.com.br the use of IMA for revascularization was unknown. Nahai et al reported a wound complication rate of $1.6 \%$ in 15595 median sternotomies and also no breast necroses. ${ }^{10}$

There are 6 breast necrosis cases reported in the world literature..$^{2,4-8}$ The authors of these studies assumed that necrosis occurred because of the direct compression force of the retractor arms on the breast. They suggested that in women with larger breasts, the minimally invasive direct coronary artery bypass grafting via small anterolateral thoracotomy may not be the approach of choice. ${ }^{5}$ In other reports, there was an unusual combination of calciphylaxis, which decreased vascular breast capacity and loss of IMA. ${ }^{4,6,8}$ One author reported a partial breast necrosis after an abscess of the sternal wound. ${ }^{2}$ After reviewing these cases, it is not clear whether the necrosis is directly related to breast vascular insufficiency.

Risk factors for breast necrosis are the use of warfarinlike agents, giant fibroadenomas, pregnancy-associated breast infarcts, fine needle aspiration or core biopsies, and vasculitis. ${ }^{4}$ Until now there have been no reports in the literature of breast necrosis associated with atherosclerotic disease. $^{4}$

A case of partial breast necrosis after myocardial revascularization and a brief survey of the literature is presented.

\section{CASE REPORT}

We present the case of a 69-year-old woman with clinically treated acute myocardial infarction who later presented with unstable angina. The coronary angiography showed occlusion of the left anterior descending coronary artery, requiring myocardial vascularization. The estimated left ventricular ejection fraction was $45 \%$ on echocardiography. Thirty-two years previously, she had undergone reduction mammaplasty with inferior pedicle fascial suspension with a vertical scar. The patient had preexisting medical illnesses including noninsulin-dependent diabetes (type 2) controlled with metformin, obesity with body mass index of $42 \mathrm{~kg} / \mathrm{m}^{2}$, autoimmune thyroiditis with 
hypothyroidism controlled with levothyroxine $100 \mathrm{mcg} /$ day; she had also smoked 20 cigarettes/day for 36 years.

Two months later, after therapeutic stabilization to reduce the myocardial ischemia, the patient underwent myocardial revascularization, using the left IMA and 3 saphenous veins. The sternotomy was closed by mechanical sutures performed with the controlled tension osteosynthesis system. The extracorporeal circulation time was 105 minutes.

The patient remained in the ICU for 18 hours, and she was hemodynamically stable, receiving dobutamine and sodium nitroprussiate for 9 hours; during this time no significant bleeding occurred. The chest tube drained 60 to $80 \mathrm{~mL} /$ hour during the first 6 hours, and there was no need for blood transfusion or isotonic crystalloid fluids. On the fourth postoperative day, she presented a cellulitis of the left leg, and partial dehiscence of the subcutaneous suture. Culture revealed Staphylococcus epidermitis in the area of the sternotomy dehiscence and in the breast necrosis. The patient received levofloxacin, without improvement of the local infection during the clinical evolution.

On the ninth postoperative day, she presented left inferior breast necrosis, confirmed by peripheral core needle biopsy (Figure 1). Core biopsy was performed with a large (14-gauge) cutting needle deployed into the breast by a rapid-fire, spring-loaded, automated biopsy instrument. The specimen consisted of a core of tissue suitable for standard histological analysis.

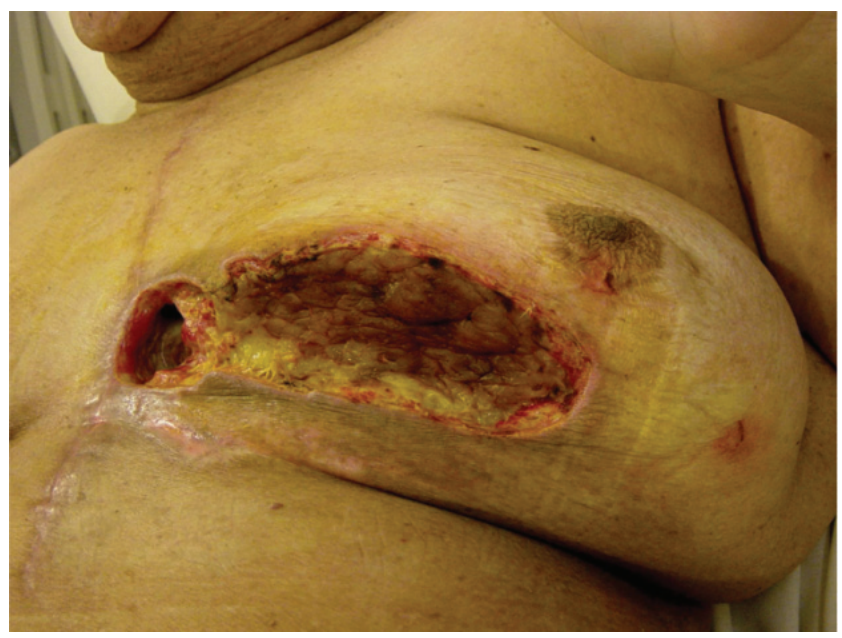

Figure 1 - Left inferior breast necrosis, confirmed by peripheral core needle biopsy, on the ninth postoperative day.

The patient received antibiotics for 3 weeks, and on the $35^{\text {th }}$ postoperative day, without clinical signs of infection, debridement was performed. Sternal instability did not occur.

Thirty days after the second surgery, she displayed only breast asymmetry (Figure 2).

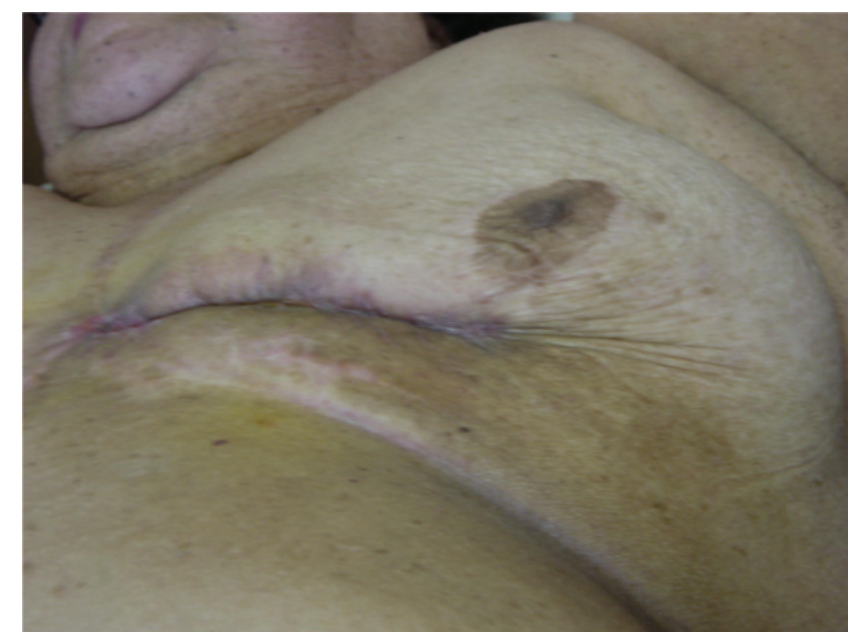

Figure 2 - Breast asymmetry 30 days after the second surgery.

\section{DISCUSSION}

The breast receives its arterial blood supply from the internal mammary artery, the lateral thoracic artery, and intercostal arteries. Normally, the breast receives $60 \%$ of its blood supply from the internal mammary artery. ${ }^{7} \mathrm{Al}-$ though anatomic studies suggest that the internal mammary artery provides approximately $60 \%$ of the arterial blood supply to the breast, normal anatomic variation may result in a breast that is supplied almost exclusively by the internal mammary artery, with minimal contributions from the intercostals and the lateral thoracic artery. ${ }^{7}$ The use of a single internal mammary artery graft has not been shown to increase the incidence of postoperative mediastinitis. However, in patients who have had some conditions that cause arterial insufficiency, such as obesity, hypertension, diabetes, and previous mammoplasty, when both internal mammary arteries are used for myocardial revascularization, the rate of mediastinitis increases..$^{\mathbf{5 , 7}}$

The patient in this report presented preoperative morbidities that have been shown in many studies to increase the risk of postoperative complications including breast necrosis. Diabetes mellitus and hypertension cause both large-vessel and small-vessel disease. ${ }^{7,8}$ Vessels such as the internal mammary and the lateral thoracic artery are also likely to be diseased in the diabetic patient, with hypertension, obesity, and hypercholesterolemia, and this may have contributed to the breast necrosis in this patient. ${ }^{7}$ Smoking is another factor that can contribute to arterial vasculitis.

Patients with obesity associated with excessively large breasts who have undergone reduction mammaplasty can have their arterial blood supply reduced as a result. ${ }^{2,7}$ The preceding breast surgery could have raised the risk of post- 
operative complications of the sternotomy. Some reports have demonstrated an increased number of complications after median sternotomy in women previously treated for breast cancer. ${ }^{11-13}$ Obesity and large breasts have been associated with increased postoperative morbidity, but there has not been any reported case of necrosis in these series. ${ }^{14}$

However, in a small study of 70 patients who had undergone conservative breast surgery for cancer and adjuvant radiotherapy, and then myocardial revascularization using IMA, there was no increased complication rate that could be related to comorbidity. ${ }^{15}$

Probably, the concomitance of risk factors for vascular disease, resulting from the hypertension, diabetes, and smoking, as well as the obesity associated with the previous mammaplasty contributed to breast necrosis.

After using IMA revascularization, breast necrosis is a rare complication and should not change the indication for the surgery. But cardiothoracic surgeons, breast surgeons, and plastic surgeons should be aware of this possibility.

\section{REFERENCES}

1. Kulbertus H, Legrand V. Women and cardiovascular diseases, particularly coronaropathies. Rev Med Liege. 1999;54:244-50.

2. Jansen DA, Zell SI, Wright MJ, Newsome RE. Poor sternal wound healing and the concomitant development of a breast abscess following midline sternotomy. Plast Reconstr Surg. 2002:345-6.

3. Jones G, Jurkiewicz MJ, Bostwick J, Wood R, Bried JT, Culberston J, et al. Management of the infected median sternotomy wound with muscle flaps: The Emory 20-year experience. Ann Surg. 1997;225:766-73.

4. Morris DJ, Fischer AH, Abboud J. Breast infarction after internal mammary artery harvest in a patient with calciphylaxis. Ann Thorac Surg. 1997;64:1469-71.

5. Har-Shai Y, Ammar R, Taran A, Barak A, Mayblum S, Uretzky G. Partial breast necrosis after MIDCABG via small anterolateral thoracotomy. Ann Thorac Surg. 1998;65:553-5.
6. Rashid A, Haj Basheer M, Khan K. Breast necrosis following harvest of internal mammary artery. Br J Plast Surg. 2004;57:366-8.

7. Gonyon DL Jr, Zenn MR, Milano CA, Levin LS. Breast necrosis following use of the internal mammary artery for coronary artery bypass. Ann Plast Surg. 2005;54:88-91.

8. Rosato F Jr, Schaner P, Chojnacki K, Rosato EL. Left breast necrosis following cardiac bypass surgery. Breast J. 2006;12:485-7.

9. Grossi EA, Culliford AT, Krieger KH, Kloth D, Press R, Baumann FG, et al. A survey of 77 major infections complications of median sternotomy: a review of 7,949 consecutive operative procedures. Ann Thorac Surg. 1985;40:214-23.

10. Nahai F, rand RP, Hester TR, Bostwick J III, Jurkiewicz MJ. Primary treatment of infected sternotomy wound with muscle flaps: a review of 211 consecutive cases. Plast Reconstr Surg. 1989;84:434-41. 
11. Yoshida K, Ohshima H, Murakami F, Matsuura A, Hibi M, Kawamu M. Two cases of coronary artery bypass grafting following radical mastectomy using internal thoracic arterial grafts. Nippon Kyobu Geka Gakkai Zasshi. 1997;45:64-6.

12. Takahashi T, Nakano S, Shimazaki Y, Kaneko M, Nakahara K, Matsuda $\mathrm{H}$, et al. Concomitant coronary bypass grafting and curative surgery cancer. Surg Today. 1995;25:131-5.

13. Erez E, Eldar S, Sharoni E, Abramov D, Sulkes A, Vidne BA. Coronary artery operation in patients after breast cancer therapy. Ann Thorac Surg. 1998;66:1312-7.
14. Pagni S, Salloum EJ, Tobin GR, VanJimbergen DJ, Spence PA. Serious wound infections after minimally invasive coronary bypass procedures. Ann Thorac Surg. 1999;67:595.

15. Gansera B, Haschemi A, Angelis I, Eichinger W, Breuer M, Keiditsel A, et al. Cardiac surgery in patients with previous carcinoma of the breast and mediastinal irradiation: is the internal thoracic artery graft obsolete? Thorac Cardiovasc Surg. 1999;47:376-80. 